\title{
Urothelial Squamous Cell Carcinoma: The Importance of Prevention
}

\author{
Jeromy Fallot ${ }^{1}$, Carla Fernandez ${ }^{2}$, Michel Campech ${ }^{3}$, Jean François Paitel $^{4}$ and Clarisse R \\ Mazzola ${ }^{1,5 *}$
}

${ }^{1}$ Department of Urology, University Hospital of Saint-Denis de la Reunion, France

${ }^{2}$ Department of Pathology, University Hospital of Saint-Denis de la Reunion, France

${ }^{3}$ Departement of Rehabilitating Medicine, University Hospital of Saint-Denis de la Reunion, France

${ }^{4}$ Department of Oncology, University Hospital of Saint-Denis de la Reunion, France

${ }^{5}$ Cancer registry, Centre for Clinical Investigation, University Hospital of Saint-Denis de la Reunion, France

*Corresponding author: Clarisse R MAZZOLA, Department of Urology, University Hospital of Saint-Denis de la Reunion, 97400 SaintDenis de la Réunion, France

To Cite This Article: Clarisse R MAZZOLA, Urothelial Squamous Cell Carcinoma: The Importance of Prevention. 2020 - 7(6). AJBSR. MS.ID.001218. DOI: 10.34297/AJBSR.2020.07.001218.

Received: 眥 March 01, 2020; Published: 眥 March 06, 2020

\author{
Abstract \\ Introduction: Squamous cell carcinomas of the urothelium are rare entities with a very bad prognosis. Quite few data are available on this type \\ of cancer outside of bilharziosis endemic countries.
}

Methods: We reviewed all the cases that were diagnosed in our university hospital from 2011 to 2016 using the pathology department records. 22 cases were identified following their ADICAP code (UV E5T0-E7T9). We removed from our study population, all the patients for whom the ADICAP code were wrong, Patients treated outside our university hospital were also excluded (2 patients).

Results: 10 cases were found in our records: 7 in the bladder, 2 in the upper urinary tract, and 1 in the bulbar urethra. Mean age at diagnosis was 55 (32-73) years old, and sex ratio was 1.6/10 patients were smokers. $90 \%$ patients had a clinical stage $\geq$ T2. One patient had bilharziosis and $3 / 10$ patients had a neurogenic bladder. $3 / 9$ patients with a bladder located lesion had a cystectomy, 1 of them had an adjuvant radio chemotherapy and 1 had an adjuvant chemotherapy. Our 2 patients with an upper tract lesion had a nephroureterectomy. Median survival was 4.8 (2-12) moist.

Conclusion: Our study confirms that squamous cell carcinoma of the urothelium is a rare entity with a very bad prognosis. Only an earlier diagnosis (in neurogenic bladder patients) and prospective and randomized studies (perhaps by regrouping all these rare cases in a single national file) could help improve the prognosis of these lesions.

Keywords: Bladder Cancer, Epidemiology, Neurogenic Bladder, Prevention, Squamous Cell Carcinoma, Urothélium, Urinary Bilharziasis, Urinary Schistosomiasis, Intra-Vesical Lithiasis.

\section{Introduction}

Bladder cancer, all pathological subtypes combined, is the eleventh cancer in frequency of diagnosis and the fourteenth cause of cancer mortality worldwide [1]. In 2015, its world incidence was $\sim 900,000$ new cases, and its mortality rate of $\sim 250,000$ deaths per year [1]. In France, it is the second urological cancer in terms of frequency after prostate cancer and represents a not insignificant public health concern [2]. Thus, with 12,305 new cases in 2015, of which $80 \%$ were in men, bladder cancer ranks fifth among the most common cancers [2]. Standardized incidence rates are 14/100 000 in men and 2.5/100000 in women, with thus a sex-ratio of 5.6 [2]. With 4961 deaths per year in 2015, of which 75\% in men, and standardized mortality rates of 4.8/100 000 in men and 1/100000 in women, this cancer represents also the fifth cancer in terms of deaths in France [2].

From a pathological point of view, muscle-invasive bladder cancers encompass a wide variety of entities including urothelial bladder carcinomas (> 90\% cases), urothelial carcinomas with glandular differentiation and/or squamous differentiation ( $\sim 5 \%)$, and squamous cell bladder carcinomas ( $~ 5 \%$ in Western countries) [3]. The pathology classification that apply to these cancers are the World Health Organization and the TNM classifications [3]. The main risk factor for the genesis of urothelial carcinoma is tobacco. The 
risk factor most frequently found in squamous cell carcinoma (and especially in its bladder location) is chronic (bladder) inflammation, whether infectious (urinary bilharziasis) or mechanical (prolonged bladder irritation by a catheter or a lithiasis, etc.), or secondary to pelvic radiotherapy [4].

From a pathological standpoint, squamous cell carcinomas differ from urothelial carcinomas in that they present an increased keratinization and intercellular bounds [5]. And there are no clinical or radiological signs allowing to distinguish the pathological subtypes of urothelial carcinomas [6]. Reunion island is an island located in the Southwest of the Indian Ocean in the southern hemisphere. It is located more than 8,000 kilometers from mainland France and is both a French department and a French overseas region, with equal access to the Healthcare systems as in mainland France. Geographically, it also belongs to the Mascarene Archipelago, about 700 kilometers east of Madagascar and 170 kilometers southwest of Mauritius - the nearest land and it is not an endemic land for urinary schistosomiasis. Roughly, its population reached nearly one million inhabitants in 2016 [7].

The main hospital infrastructure of the island is the University Hospital (CHU) of Reunion which is divided into two sites: The North site (in the city of Saint-Denis) and the South site (in the city of Saint-Pierre). The objective of our work was to study the management of squamous cell carcinoma of the urinary tract in Reunion Island from 2011 to 2016.

\section{Material and Methods}

\section{Study Type}

Observational Retrospective Study.

\section{Study Population}

Inclusion criteria: We retrospectively identified all the cases of squamous cell carcinoma of the

urothelium identified at the University Hospital (CHU) of Saint Denis and Saint-Pierre de la Reunion from 2011 to 2016. In this prospect, we consulted the database of the pathology department of our University Hospital Center. The keywords in the search engine of this database we used were "squamous cell carcinoma" and "bladder". The ADICAP (Association for the Development of Informatics in Pathological Cytology and Anatomy) codes we used to be UV EST0-E7T9. Due to the small number of patients with a squamous cell carcinoma of the bladder, we also included in our analysis the patients with a squamous cell carcinoma of the upper urinary system and urethra.

Exclusion criteria: We excluded from our database all the patients whose medical records were

not accessible due to a treatment performed outside of Reunion and all the records for which the pathology report did not actually correspond to a squamous cell carcinoma of the urothelium but to another histopathological entity and in particular to a urothelial carcinoma with squamous inflections.

Main outcome variables: For all the files that were included in our analysis, we collected these

information: (i) sex, (ii) age, (iii) risk factors for a squamous cell carcinoma of the urothelium (tobacco, urinary schistosomiasis, HPV, neurological bladder, intra-vesical lithiasis, indwelling bladder catheter or long-term pubic catheter), (iv) symptomatology at the time of diagnosis, (v) endoscopic and CT appearance at diagnosis, (vi) pathology of the operative specimen in operated patients, (vii) type of treatment delivered and (viii) follow-up information (duration of follow-up, recurrence, status at the end of the study period (deceased/alive being followed-up /alive and cured/loss of sight).

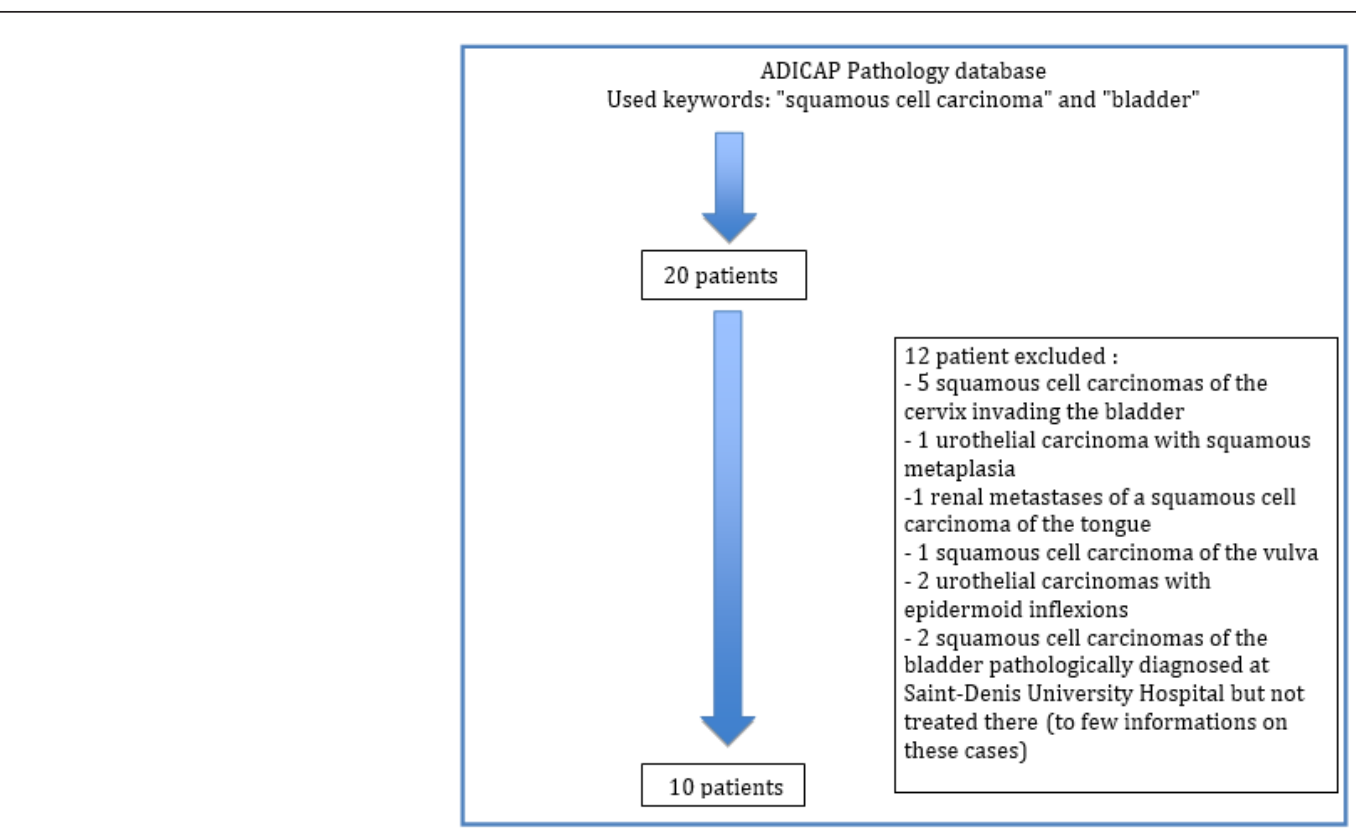

Figure 1: Selection of our study population 


\section{Statistical Methods}

Our study being a retrospective cross-sectional observational study, a descriptive statistical methodology was used.

\section{Results}

\section{Study Population}

All in all, 22 files corresponding to the above mentioned ADICAP codes were identified. Of these 22 files, 12 were excluded (Figure 1):

I. 5 corresponded to a squamous cell carcinoma of the cervix invading the bladder,

II. 1 was a urothelial carcinoma with squamous metaplasia,

III. 1 was a renal metastases of a squamous cell carcinoma of the tongue,

IV. 1 corresponded to a squamous cell carcinoma of the vulva,

V. 2 were in fact urothelial carcinomas that had been wrongly assigned to this ADICAP code, including one with squamous inflection.
VI. 2 patients whose pathological diagnosis was made at the University Hospital but whose treatment was performed in another center (Madagascar) with an impossible access to their medical files.

In the end, ten patients could be included in our study, among them 7 pure squamous cell carcinomas of the bladder, 2 squamous cell carcinomas of the upper excretory ducts and 1 squamous cell carcinoma affecting the urethra. The median age at diagnosis was 55 years (32-72) and the sex ratio was 1 (5 women for 5 men).

\section{Risk Factors}

In our study, the risk factors of squamous cell carcinoma of the urinary tract were: tobacco (six patients), chronic bilharziasis infection (one patient), chronic HPV infection (one patient) [8], chronic bladder inflammation by an indwelling catheter and/or by the presence of long-term intra vesical lithiasis in a context of neurogenic bladder (three patients): a patient with a traumatized spinal cord after a car accident, a hemiplegic patient after a carotid aneurysm rupture and a patient with a congenital encephalopathy. Three patients had two risk factors (Table 1).

\begin{tabular}{|c|c|c|c|c|}
\hline Patient & Age (Years) & Sex & Risk Factors & Presentation \\
\hline 1 & 45 & M & HPV & Dysuria (urethral stricture) \\
\hline 2 & 57 & M & Tobacco & Lower back pain \\
\hline 3 & 72 & $\mathrm{M}$ & Tobacco & ICS, abdominal pain \\
\hline 4 & 55 & M & Tobacco, Bilharziasis & ICS, hematuria \\
\hline 5 & 72 & $\mathrm{~F}$ & 0 & ICS, abdominal pain, hematuria \\
\hline 6 & 59 & $\mathrm{~F}$ & Chronic UI & ICS, abdominal pain, hematuria, ARF \\
\hline 7 & 64 & $\mathrm{~F}$ & Tobacco, neurogenic bladder & ICS, hematuria \\
\hline 8 & 59 & $\mathrm{~F}$ & Tobacco & ICS \\
\hline 9 & 32 & M & Tobacco, neurogenic bladder & ICS, ARF \\
\hline 10 & 34 & $\mathrm{~F}$ & Chronic UI, neurogenic bladder & Abdominal pain, hematuria, ARF \\
\hline
\end{tabular}

Legends: HPV = Human Papilloma Virus; ICS = Impaired Clinical Status; IRA = Acute Renal Failure; IU = Urinary infection.

\section{Clinical presentation}

At the time of diagnosis, the most common symptom was gross hematuria (six patients) and impairment of clinical status (significant weight loss $>10 \%$ ) in five patients, associated with abdominal or lumbar pain (five patients). Urinary symptoms such as pollakiuria or dysuria and urinary tract infections were present in two patients. Three patients had acute obstructive renal failure at the time of diagnosis.

\section{Endoscopy}

Endoscopic examination revealed sessile polyps larger than three centimeters in four patients, less than three centimeters in three patients (including the patient with a bulbar urethra carcinoma), and no polyp in one of the two patients with an upper excretory duct disease. As for the second patient presenting an involvement of the upper urinary tract, there was no urethrovesical fibroscopy result in the records. Cystoscopy findings were a single polyp in five patients, two to three polyps in two patients, and one patient with a whole bladder involvement.

\section{Scannographic Aspect}

Nine of the ten patients in our study had an abdominopelvic CT scan in their file. There was an uretero-hydronephrosis in four patients (associated with an acute renal failure in three cases, the last patient probably having a chronic dilatation of the upper urinary tract upstream from a ureteral tumor, with preserved renal function). We also observed the presence of lymphadenopathies in four patients (at the ilio obturator, inguinal, abdominal and interaortico-caval levels). Hepatic, adrenal and vertebral metastases (T12) were also found in a same patient with an upper excretory tract tumor. 


\section{Biopsies}

Eight out of ten patients had endoscopic biopsies before treatment (endoscopic bladder resection or diagnostic ureteroscopy). In our series, two patients were treated surgically without previous biopsies. One case was in a patient with a large tumor of the upper excretory duct (initially suspected to be a kidney cancer) and the other case was in a patient with a history of neurogenic bladder (initially treated with a bladder enlargement cystoplasty and then with total cystectomy for non-functional bladder responsible for multiple infections), with incidental discovery of the squamous cell urothelial carcinoma on the specimen (Table 2).

\section{Therapeutic Management and Follow-Up}

An overview of the treatment to which each patient was assigned and the status of each patient at last follow-up are given in (Table 2).

\begin{tabular}{|c|c|c|c|c|c|c|c|c|c|c|}
\hline $\begin{array}{l}\text { Pa- } \\
\text { tient }\end{array}$ & $\begin{array}{l}\text { Biopsy pT } \\
\text { stage }\end{array}$ & Surgery & $\begin{array}{l}\text { Adjuvant Ra- } \\
\text { diotherapy }\end{array}$ & $\begin{array}{l}\text { Adjuvant Chemo- } \\
\text { therapy }\end{array}$ & $\begin{array}{l}\text { Pathology } \\
\text { Stage }\end{array}$ & $\begin{array}{l}\text { Reccu- } \\
\text { rence }\end{array}$ & $\begin{array}{l}\text { Local Re- } \\
\text { currence }\end{array}$ & $\begin{array}{l}\text { Distant } \\
\text { Recur- } \\
\text { rence }\end{array}$ & $\begin{array}{c}\text { Last Fol- } \\
\text { low-up Status }\end{array}$ & $\begin{array}{l}\text { Survival } \\
\text { (months) }\end{array}$ \\
\hline 1 & pTis & $\begin{array}{l}\text { End-to-end } \\
\text { ure- } \\
\text { troplasty }\end{array}$ & Yes & No & $\begin{array}{l}\text { pTis + } \\
\text { micro-infiltra- } \\
\text { tions }\end{array}$ & No & No & No & Alive & 18 \\
\hline 2 & pT2 & Right NUT & No & No & pT3Nx & Yes & Yes & No & Alive & 42 \\
\hline 3 & N/A & Left EN & No & No & pT4Nx & Yes & Yes & Yes & Dead & 2 \\
\hline 4 & pT2 & Cystectomy & No & Yes & pT4aN0 & Yes & No & Yes & Alive & 18 \\
\hline 5 & pT2 & Cystectomy & No & No & pT3bN0 & No & No & No & Dead & 3 \\
\hline 6 & $\mathrm{~N} / \mathrm{A}$ & Cystectomy & Yes & No & pT3aNx R1 & Yes & Yes & Yes & LOS & LOS \\
\hline 7 & pT2 & No & Yes & No & $\mathrm{N} / \mathrm{A}$ & Yes & No & Yes & LOS & LOS \\
\hline 8 & pT2 & No & Yes & Yes & $\mathrm{N} / \mathrm{A}$ & Yes & Yes & Yes & Dead & 5 \\
\hline 9 & pT2 & No & No & No & $\mathrm{N} / \mathrm{A}$ & Yes & Yes & Yes & Dead & 12 \\
\hline 10 & pT2 & No & No & No & N/A & Yes & Yes & Yes & Dead & 2 \\
\hline
\end{tabular}

Legends: NUT= Nephroureterectomy; EN= Enlarged Nephrectomy; N/A=Not Applicable; LOS=Lost-of-sight.

\section{Pathological Analysis of the Retrieved Specimens}

As for the patients who underwent surgery, the final pathology report of the retrieved specimens has revealed an understaging of the disease by biopsies. Despite no important delay between biopsies and surgeries, the definitive stages of the three cystectomy pieces were respectively: pT4aN0Mx R0 (invasion of the prostate and the prostatic urethra), pT3bN0Mx R0 and pT3aNxMx R1 (R1 on the ureter). The complete analysis found vascular emboli on the three specimens. More information on the pathology reports of the retrieved specimen is shown in (Table 2).

\section{Discussion}

Squamous cell carcinoma, regardless of its location within the urothelium, is an aggressive tumor with a poor prognosis. Unlike the rest of Africa (and more particularly Egypt), where the most common etiological factor is urinary schistosomiasis, Reunion is not an area affected by Schistosoma Haematobium. But very little else is known on the epidemiology of this disease there. In our retrospective analysis, we have shown that squamous cell carcinomas of the urothelium in Reunion: (i) affect a rather young population (55 years), (ii) indifferently in both sexes (sex ratio
1:1), ( iii) with identical risk factors to areas of the world that are not affected by Schistosoma Haematobium, (iv) are most often diagnosed at an infiltrating stage, (v) and most often have a poor prognosis (50\% survival at 18 months).

First, in our study, patients with squamous cell carcinoma of the urothelium were about 55 years old (32-73). Our study population was therefore slightly younger than the populations of patients with squamous cell carcinoma of the urothelium usually described in the literature. In the series of Gluck et al. [9] for example (13 patients) performed in Romania, the average age was 59 years old [9]. In the series of Balci et al. [10] (60 patients) in Turkey, the mean age was 59.4 years $( \pm 8.6)$ [10]. In larger series such as that of Ploeg et al. [11] (730 patients) on a national Netherlands database, the average age of patients was even higher: 70.6 years $( \pm 13.1$ ) [11].Then, in our series, the sex ratio was $1: 1$, whereas a male predominance is usually observed in this type of cancer. In a meta-analysis of more than 150 papers performed by Abol-Enein et al. [12], a sex ratio of 1.4:1 was indeed reported [12]. In another series from Spain, published by Pons et al. [13] the sex ratio between men and women was 1.25-1.8:1 [13]. We hypothesize that a difference in smoking exposure may be responsible for these differences. 
In addition, the risk factors associated with squamous cell carcinoma in our series were the same as those described in the literature in areas not affected by Schistosoma Haematobium: tobacco, neurogenic bladder (with chronic bladder irritation: lithiasis, indwelling urinary catheter) [4,13-16]. The risk factor mainly found in our series was having a neurogenic bladder. The only case of a patient with a history of Schistosoma Haematobium infection in our study was a patient operated at the University Hospital of Saint-Denis de la Reunion but originally from Mali and having lived much of his youth in this country. In our series, $90 \%$ of tumors were pure squamous cell carcinomas except for one case of predominantly squamous cell carcinoma and all were invasive at diagnosis (minimum pT2 stage). These results seem consistent with those of Ploeg et al. [11] which report $87.5 \%$ of invasive cancers at diagnosis out of the 730 cases of squamous cell carcinomas of the urothelium found in the Dutch cancer registry [11]. A minimum pT2 stage is similarly described in the series of Xylinas et al. [17] and in the series of Lagwinski et al. [18], in respectively $89 \%$ and $98 \%$ of the cases at diagnosis $[17,18]$.

More specifically, and more pejoratively, in our series, the final pathological analysis of the operative specimens found a pT3 stage in three patients (50\%) and a pT4 stage in two patients (33\%). In the series of Xylinas et al. [17] and Lagwinski et al. [18] pT3 stage rates were $47.6 \%$ and $60 \%$, respectively, and pT 4 stage rates were $15.4 \%$ and $7 \%$, respectively $[17,18]$. The highest proportion of pT4 stage in our series, subject to the small size of our series, could be a reflection of a later diagnosis and therapeutic management in our more rural population.

Not surprisingly, from a therapeutic point of view, the patients who in our series were able to benefit from surgical treatment had the best results in terms of survival, since three out of six patients were alive at least 18 months after surgery (50\% survival at 18 months) despite the occurrence of a recurrence in two of them. These patients were in better general condition according to the WHO classification, allowing general anesthesia and a cystectomy (two out of three cases) and presenting tumors deemed extirpable in the preoperative assessment. In the series published in the literature, 5-year survival rates ranging from $10 \%$ to $50 \%$ have been reported [5,9,12,13,18-24]. Given the small size of our cohort, further comparisons of our survival statistics would seem risky.

Regarding the adjuvant treatments after surgery in our series, two patients had adjuvant radiotherapy. One of these patients had a urethral location of his disease and had no recurrence. The second patient had a locoregional recurrence after a cystectomy with positive margins on a ureter and could not receive chemotherapy because of a poor general condition. This patient was then lost to follow-up. Another patient received adjuvant chemotherapy and despite recurrence of the disease, was alive 18 months postoperatively (patient infected with Schistosoma Haematobium).
The initiation of these multimodal treatments seemed to us in accordance with the usual treatments described in the literature, for this aggressive disease, where the majority of deaths occur after a rapid locoregional recurrence, favored by either the advanced stage of the disease and/or ganglionic invasion and/or positive surgical margins [13,21,24-27]. Some authors like Willis et al. [23] report a benefit of adjuvant radiotherapy on 5-year disease-free survival ranging from $44 \%$ to $49 \%$ compared to $25 \%$ in patients only getting surgery.

In our series, no patient received neoadjuvant therapy. In the literature, the potential benefit of neoadjuvant treatment before surgery remains highly debated in squamous cell carcinoma of the urothelium $[13,20,21,24]$. Some authors have reported an improvement in 5-year survival (from 34\% to 50\%) in patients treated with neo-adjuvant radiotherapy $[13,21,23]$. However, and as often in such rare diseases, these results were obtained in small cohorts [21,22,24,27]. For other authors such as Ehdaie et al. [26], on the other hand, squamous cell carcinoma of the urothelium is resistant to radiotherapy and chemotherapy (and especially in its bladder location) [26]. Other authors have similarly reported an inefficiency of this treatment in this disease [12,24,26,27].

Among the patients of our study who did not get surgery, one patient was treated with radiotherapy and chemotherapy and died at 5 months. Another was treated with radiotherapy alone and was lost to follow-up. The medical literature is finally reporting relatively few effective therapeutic alternatives in non-operable patients. In 2007, Abol Enein et al. [12] described a low response rate to (M-VAC) chemotherapy in patients with squamous cell subtype compared to pure urothelial carcinoma. For some others, radiotherapy with or without chemotherapy may be a therapeutic alternative but remains a strategy that is inferior to surgery [28]. For Kassouf et al. [24], in patients not accessible to surgical treatment, radiotherapy and/or chemotherapy should be systematically proposed as it is the case for the management of squamous cell carcinomas affecting other organs.

Among the limitations of this work, we must say that it is a retrospective study, and that the size of our study population was small (related to the low frequency of the disease and monocentric recruitment). However, some observations made in this series could allow us to identify some ways to improve the care pathway of patients, especially patients with a neurogenic bladder. More as none of the neurogenic bladder patients in our study had had an annual urethrovesical fibroscopic follow-up, which likely contributed to a delayed diagnosis. To our knowledge, this is the first descriptive study of squamous cell carcinomas of the urothelium treated at the University Hospital of Saint Denis and Saint-Pierre de la Reunion. Despite the limitations of our work that we have explained above, we hope that an optimization of the care pathway of the patients with a neurogenic bladder can be achieved in partnership with our 
fellow general practitioners and rehabilitative physicians, including this annual fibroscopic follow-up.

We also hope that our work will serve as a tool for the creation of a full prospective registry of urological cancers in Reunion Island, essential basis for the monitoring and the improvement of the management of not only the squamous cell carcinomas of the urothelium, but more generally the urological cancers.

\section{Conclusion}

In our experience, squamous cell carcinoma of the urinary tract is a rare malignant tumor occurring in young patients and is associated with a poor prognosis. Even though its risk factors are well identified, diagnosis occurs too often too late in the disease course with most of the time already a bad prognosis stage at diagnosis. Surgical treatment with cystectomy, in the few of our cases where it was possible, allowed us to obtain a median survival of 18 months. An optimization of the care pathway of neurological patients on our island, including a systematic annual urethrovesical control fibroscopy, would be suitable to improve our outcome results on this disease.

\section{Acknowledgements}

Our research itself received no funding.

But we thank the University Hospital of Saint-Denis de la Réunion, France for paying the publication fees of this paper.

\section{Conflicts of Interest}

All authors have no conflict of interest to disclose.

\section{Ethics, Consent and Permissions}

In accordance with European regulation, French observational studies from data obtained without any additional therapy or monitoring procedure, do not need the approval of an IRB. Also, this study reports the results of an audit of our activity and outcomes regarding patients with a squamous cell carcinoma of the urothelium treated at our hospital. Under the French law, the physicians of a department do not require a written consent from the patients of this department to access their files when the study is designed at auditing the clinical activity of the department.

\section{Data and Material Availability}

Our unidentified dataset is available upon request in the Urology department of the University Hospital of Saint-Denis de la Réunion.

\section{References}

1. Klotz L, Brausi MA (2015) World Urologic Oncology Federation Bladder Cancer Prevention Program: a global initiative. Urol Oncol 33(1): 25-29.

2. (2015) Cancers in France. Institute National Du Cancer, France

3. Epstein JI, Amin MB, Reuter VE (2003) Bladder biopsy interpretation. Lippincott Williams \& Wilkins, Philadelphia, USA.
4. Zerbib M, Bouchot O (2002) Epidermoid carcinoma of the bladder. Prog En Urol J Assoc Fr Urol Société Fr Urol 12(5): 1115-1120.

5. Chalasani V, Chin JL, Izawa JI (2009) Histologic variants of urothelial bladder cancer and nonurothelial histology in bladder cancer. Can Urol Assoc J 3(6 Suppl 4): 193-198.

6. Resina RG, Bernal MLS, Espejo MPP, Corchero FJR, Salido EA, et al. (2006) Squamous cell carcinoma of the bladder. Review of our case series. Arch Esp Urol 59(8): 785-790.

7. Ajir S, Insee (2013) Population growth slows Demographic review. Insee, France pp.33.

8. Cobos C, Figueroa JA, Mirandola L, Colombo M, Summers G, et al. (2014) The role of human papilloma virus (HPV) infection in non-anogenital cancer and the promise of immunotherapy: a review. Int Rev Immunol 33(5): 383-401.

9. Gluck G, Hortopan M, Stănculeanu D, Chiriță M, Stoica R, et al. (2014) Comparative study of conventional urothelial carcinoma, squamous differentiation carcinoma and pure squamous carcinoma in patients with invasive bladder tumors. J Med Life 7(2): 211-214.

10. Balci U, Ozer K, Gorgel SN, Sefik E, Girgin C, et al. (2013) Do pure squamous cell carcinomas and urothelial carcinomas have similar prognosis after radical cystectomy? World J Urol 31(5): 1177-1182.

11. Ploeg M, Aben KK, Hulsbergen van de Kaa CA, Schoenberg MP, Witjes JA, et al. (2010) Clinical epidemiology of nonurothelial bladder cancer: analysis of the Netherlands Cancer Registry. J Urol 183(3): 915-920.

12. Enein HA, Kava BR, Carmack AJK (2007) Nonurothelial cancer of the bladder. Urology 69(1 Suppl): 93-104.

13. Pons F, Orsola A, Morote J, Bellmunt J (2011) Variant forms of bladder cancer: basic considerations on treatment approaches. Curr Oncol Rep 13(3): 216-221.

14. West DA, Cummings JM, Longo WE, Virgo KS, Johnson FE, et al. (1999) Role of chronic catheterization in the development of bladder cancer in patients with spinal cord injury. Urology 53(2): 292-297.

15. Parra J, Drouin S, Comperat E, Misraï V, Van Glabeke E, et al. (2007) Bladder cancer in neurological patients: analysis of a single-centre series. Prog En Urol J Assoc Fr Urol Société Fr Urol 17(7): 1333-1336.

16. Khalaf I, Shokeir A, Shalaby M (2012) Urologic complications of genitourinary schistosomiasis. World J Urol 30(1): 31-38.

17. Xylinas E, Rink M, Robinson BD, Lotan Y, Babjuk M, et al. (2013) Impact of histological variants on oncological outcomes of patients with urothelial carcinoma of the bladder treated with radical cystectomy. Eur J Cancer Oxf Engl 49(8): 1889-1897.

18. Lagwinski N, Thomas A, Stephenson AJ, Campbell S, Hoschar AP, et al. (2007) Squamous cell carcinoma of the bladder: a clinicopathologic analysis of 45 cases. Am J Surg Pathol 31(12): 1777-1787.

19. Porten SP, Willis D, Kamat AM (2014) Variant histology: role in management and prognosis of nonmuscle invasive bladder cancer. Curr Opin Urol 24(5): 517-523.

20. Black PC, Brown GA, Dinney CPN (2009) The impact of variant histology on the outcome of bladder cancer treated with curative intent. Urol Oncol 27(1): 3-7.

21. El-Sebaie M, Zaghloul MS, Howard G, Mokhtar A. (2005) Squamous cell carcinoma of the bilharzial and non-bilharzial urinary bladder: a review of etiological features, natural history, and management. Int J Clin Oncol 10(1): 20-25.

22. Rausch S, Lotan Y, Youssef RF (2014) Squamous cell carcinogenesis and squamous cell carcinoma of the urinary bladder: a contemporary review with focus on nonbilharzial squamous cell carcinoma. Urol Oncol 32(1): 11-16. 
23. Willis DL, Porten SP, Kamat AM (2013) Should histologic variants alter definitive treatment of bladder cancer? Curr Opin Urol 23(5): 435-443.

24. Kassouf W, Spiess PE, Siefker Radtke A, Swanson D, Grossman HB, et al. (2007) Outcome and patterns of recurrence of nonbilharzial pure squamous cell carcinoma of the bladder: a contemporary review of The University of Texas M D Anderson Cancer Center experience. Cancer 110(4): 764-749.

25. Izard JP, Siemens DR, Mackillop WJ, Wei X, Leveridge MJ, et al. (2015) Outcomes of squamous histology in bladder cancer: a population-based study. Urol Oncol 33(10): 7-13.
26. Ehdaie B, Maschino A, Shariat SF, Rioja J, Hamilton RJ, et al. (2012) Comparative outcomes of pure squamous cell carcinoma and urothelial carcinoma with squamous differentiation in patients treated with radical cystectomy. J Urol 187(1): 74-79.

27. Dahm P, Gschwend JE (2003) Malignant non-urothelial neoplasms of the urinary bladder: a review. Eur Urol 44(6): 672-681. 